\title{
JENIS ATAP, SUHU DAN KELEMBABAN DALAM RUMAH
}

\author{
Fatimah, Juanda, Imam Santoso \\ Poltekkes Kemenkes Banjarmasin Jurusan Kesehatan Lingkungan \\ Jl. H. Mistar Cokrokusumo No.1A Banjarbaru kalimantan Selatan 70714 \\ E-mail: $\underline{\text { mdfatim07@Gmail.com }}$
}

\begin{abstract}
Abstrack: Type of roof, temparature and humidity in the house. The roof is the largest element that receives sun exposure. The type of roof affects the amount of heat energy that can be absorbed of reflected. The temperature and humidity in the room. This study aims to determine the relationship between the type of roof with temperature and humidity in the house in the Badaun village. This research use cross sectional design with variation of roof type was leaf, asbestos and iron sheeting. The study population was 68 houses and was analyzed using Somers'd test.The results showed that the proportion of leaf roof, asbestos and iron sheeting were $36.8 \%, 10.3 \%$ and $52.9 \%$, respectively. Average home room temperature using a leaf roof type of $29.6^{\circ} \mathrm{C}, 32^{\circ} \mathrm{C}$ asbestos roof and $32.1^{\circ} \mathrm{C}$ iron sheeting roof. The average humidity of the house that uses the leaf roof is $72.28 \%$, asbestos $55.7 \%$ and iron sheeting 57.3\%. The results of the analysis using the Somers'd test proved statistically there is a strong relationship between the type of roof of the house (leaves, asbestos and zinc) with the temperature and humidity in the house in Badaun Village, Tapin District. Every home that uses zinc and asbestos roof 27 times the risk $(O R=27)$ hotter than the house using a leaf roof. Efforts that can be done to cope with higher temperatures and humidity is in the effort to install the ceiling of the house and always open the doors and windows every morning.
\end{abstract}

Keywords: Type of roof; Temperature; Humidity

\begin{abstract}
Abstrak: Jenis atap, suhu dan kelembaban dalam rumah. Atap merupakan elemen terbesar yang menerima paparan sinar matahari. Jenis atap mempengaruhi jumlah energi panas yang bisa diserap atau dipantulkan. Suhu atap mempengaruhi suhu dan kelembaban di dalam ruangan. Penelitian ini bertujuan untuk mengetahui hubungan antara jenis atap dengan suhu dan kelembaban di dalam rumah di Desa Badaun. Penelitian ini menggunakan rancangan potong lintang dengan variasi jenis atap adalah daun, asbes, seng. Populasi penelitian berjumlah 68 rumah dan dianalisis menggunakan uji Somers'd. Hasil penelitian menunjukkan bahwa proporsi jenis atap daun, asbes dan seng masing-masing sebesar 36,8\%, 10,3\% dan 52,9\%. Rata-rata suhu ruangan rumah yang menggunakan atap jenis daun $29,6^{\circ} \mathrm{C}$, atap asbes $32^{\circ} \mathrm{C}$ dan atap seng $32,1^{\circ} \mathrm{C}$. Rata-rata kelembaban ruangan rumah yang menggunakan atap daun 72,28\%, asbes 55,7\% dan seng 57,3\%. Hasil analisis menggunakan uji Somers'd terbukti secara statistik ada hubungan kuat antara jenis atap rumah (daun, asbes dan seng) dengan suhu dan kelembaban dalam rumah di Desa Badaun Kabupaten Tapin. Setiap rumah yang menggunakan atap seng dan asbes 27 kali berisiko $(O R=27)$ lebih panas dari pada rumah yang menggunakan atap daun. Upaya yang dapat dilakukan untuk mengatasi suhu dan kelembaban yang lebih tinggi yaitu di upayakan dengan memasang plafon rumah dan selalu membuka pintu serta jendela setiap pagi hari.
\end{abstract}

Kata Kunci: Jenis atap; Suhu; Kelembaban

\section{PENDAHULUAN}

Dalam ruang sebuah bangunan, secara umum dibentuk oleh tiga elemen pembentuk ruang yaitu bidang alas, bidang dinding, bidang langit-langit atau atap (over head plane). Komponen yang harus dimiliki rumah sehat antara lain adalah atap rumah [1]. Atap rumah berfungsi sebagai pelindung dari panas sinar matahari, sebagai penahan dari air hujan, sebagai pelindung dari hembusan angin dan sebagai pelindung dari hembusan debu[2]. 
Atap adalah mahkota suatu bangunan sehingga peran atap sangat dominan dalam keberhasilan suatu bangunan sebagai shalter atau perlindungan. Aspek thermal didapatkan perhitungan sistematis bahwa $2 / 3$ panas yang terjadi didalam bangunan tertransmisi melalui atap ${ }^{[3]}$.

\section{BAHAN DAN CARA PENELITIAN}

Rancangan bangun dalam penelitian ini adalah cross sectional studies untuk mempelajari dinamika korelasi antara faktor-faktor resiko dengan efek. Populasi penelitian ini adalah seluruh rumah yang berada di Desa Badaun Tapin Utara Kabupaten Tapin. Teknik sampel yang digunakan yaitu saturation sampling, semua populasi sebagai sampel[4].
Pengukuran dilakukan dua kali pengukuran, pertama dilakukan antara jam 09.00-12.00 WITA, kedua antara jam 13.00-16.00 WITA yaitu pada tempat berkumpulnya keluarga.

Analisis data berupa analisis univariat dan analisis bivariat [5]. Metode pengumpulan data penelitian ini dengan cara observasi jenis atap dan pengukuran suhu dan kelembaban.

Data yang diperoleh diolah secara manual, disajikan dalam bentuk tabel distribusi frekuensi [6]. Untuk mengetahui hubungan jenis atap dengan suhu dan kelembaban dalam ruangan, dianalisis secara statistik yaitu dengan bantuan komputer menggunakan Uji Korelasi Somers'd dan Odds Ratio[7].

\section{HASIL PENELITIAN DAN PEMBAHASAN}

Berikut hasil identifikasi jenis atap yang digunakan di Desa Badaun Tapin Utara Kabupaten Tapin

Tabel 1. Distribusi Frekuensi Jenis Atap Rumah

\begin{tabular}{llcc}
\hline No & Jenis Atap & $\begin{array}{c}\text { Frekuensi } \\
\text { (f) }\end{array}$ & $\begin{array}{c}\text { Persen } \\
(\%)\end{array}$ \\
\hline 1 & DaunRumbia & 25 & 36,8 \\
2 & Asbes & 7 & 10,3 \\
3 & Seng & 36 & 52,9 \\
\hline \multicolumn{2}{r}{ Jumlah } & 68 & 100
\end{tabular}

Pada tabel 1. Hasil Observasi Jenis atap yang paling banyak digunakan di desa Badaun pada tahun 2018 adalah jenis atap seng. Kecenderungan rumah yang menggunakan atap daun beralih menggunakan atap seng, sehingga di Desa Badaun mayoritas rumah menggunakan atap jenis seng karena sebagian besar masyarakat beralasan atap seng lebih awet dibandingkan dengan atap jenis lain seperti daun dan asbes.

Hasil pengukuran suhu ruangan rumah di Desa Badaun :

Tabel 2. Distribusi Frekuensi Suhu Ruangan Berdasarkan Jenis Atap

\begin{tabular}{llclc}
\hline No & Jenis Atap & $\mathrm{MS} / \bar{x}$ & $\mathrm{TMS} / \bar{x}$ & $\Sigma$ \\
\hline 1. & Daun rumbia & $21 / 29,7^{\circ} \mathrm{C}$ & $4 / 31,25^{\circ} \mathrm{C}$ & 25 \\
2. & Asbes & 0 & $7 / 32,5^{\circ} \mathrm{C}$ & 7 \\
3. & Seng & $7 / 29,7^{\circ} \mathrm{C}$ & $29 / 32,3^{\circ} \mathrm{C}$ & 36 \\
& Jumlah & 28 & 40 & 68 \\
\hline
\end{tabular}

Pada tabel 2. Hasil Pemeriksaan suhu rumah yang jenis atap daun $84 \%$ memenuhi syarat (suhu $<30^{\circ} \mathrm{C}$ ), jenis atap asbes tidak memenuhi syarat (suhu > $30^{\circ} \mathrm{C}$ ) dan atap seng hanya $19,4 \%$ yang memenuhi syarat. Suhu tertinggi pada ruangan rumah yang menggunakan jenis atap seng sebesar $36^{\circ} \mathrm{C}$ dan suhu terendah pada ruangan yang menggunakan jenis atap daun sebesar $25^{\circ} \mathrm{C}$. Pada ketiga jenis 
atap tersebut persentase tertinggi suhu memenuhi syarat pada atap daun.
Hasil pengukuran kelembaban ruangan rumah di Desa Badaun dapat dilihat pada tabel di bawah ini:

Tabel 3. Distribusi Frekuensi Kelembaban Ruangan Berdasarkan Jenis Atap

\begin{tabular}{clccc}
\hline No & Jenis Atap & MS $/ \bar{x}$ & TMS $/ \bar{x}$ & $\Sigma$ \\
\hline 1 & Daun Rumbia & $5 / 56,4 \%$ & $20 / 76,25 \%$ & 25 \\
2 & Asbes & $6 / 53,7 \%$ & $1 / 68 \%$ & 7 \\
3 & Seng & $28 / 50,92 \%$ & $8 / 79,8 \%$ & 36 \\
& Jumlah & 39 & 29 & 68 \\
\hline \multicolumn{2}{l}{ Catatan: persyaratan menurut Permenkes RI No. 1077/Menkes/PER/V/2011 }
\end{tabular}

Pada tabel 3. Hasil Pemeriksaan kelembaban tertinggi pada ruangan rumah yang menggunakan jenis atap daun yaitu 88\% dan kelembaban terendah pada ruangan yang menggunakan jenis atap seng yaitu $45 \%$. Pada ketiga jenis atap tersebut persentase tertinggi kelembaban memenuhi syarat adalah pada atap seng.

Berdasarkan hasil uji korelasi Somers'd, terbukti secara statistik ada hubungan jenis atap rumah (daun, asbes dan seng) dengan suhu karena Ho ditolak (nilai $p=0,000<\mathrm{a}=0,05$ ) dan nilai $\mathrm{r}$ adalah 0,512 maka koefisien korelasi antara kedua variabel hubungan kuat. Korelasi yang terjadi antara dua variabel berupa korelasi positif yaitu apabila rumah yang menggunakan jenis atap asbes dan seng suhu akan (naik) lebih tinggi. Pada Hipotesis kedua Ho ditolak artinya ada hubungan jenis atap rumah (daun, asbes dan seng) dengan kelembaban, dengan nilai $r=-0,463$. Berdasarkan hasil tersebut maka koefisien korelasi antara kedua variabel hubungan sedang. Korelasi yang terjadi antara dua variabel berupa korelasi negatif yaitu apabila rumah yang menggunakan jenis atap asbes dan seng kelembaban akan turun (rendah).

Pada rumah yang menggunakan atap seng terdapat $42,6 \%$ rumah yang tidak memenuhi syarat dari total sampel pengamatan (suhu $>30{ }^{\circ} \mathrm{C}$ ). Hal ini dikarenakan atap yang menjadi penerima terbesar radiasi sinar matahari, yang dapat memantulkan atau menyerap panas dan di teruskan ke area yang lebih dingin (dalam ruangan/ bawah atap) [2].

Radiasi matahari adalah penyumbang jumlah panas terbesar yang masuk kedalam bangunan. Jenis atap memiliki radiasi matahari dan serapan kalor yang berbeda, permukaan atap yang menyerap kalor tertinggi ialah seng yaitu 92\% dan asbes 83\%. Semakin besar serapan kalor semakin besar pula panas yang di teruskan ke dalam ruangan [8].

Adapun Rumah yang beratap seng $10,3 \%$ memenuhi persyaratan, karena rumah tersebut menggunakan plafon kayu. Panas atap yang terkena radiasi sinar matahari tidak langsung mengalirkan keruangan rumah, namun akan tertahan oleh plafon sehinggan kondisi suhu dalam ruangan akibat atap tetap terjaga.

Atap seng terbuat dari baja tipis yang diberi lapisan zeng secara elektrolisa yang dapat menyerap panas dan meneruskan kedalam ruangan rumah sehingga rumah yang menggunakan atap seng terasa lebih panas. Kenyamanan temperatur (thermal comfort) merupakan hal penting dalam menciptakan suatu kenyamanan di dalam ruang [9].

Rumah sehat yang memenuhi persyaratan fisiologis yaitu suhu tidak melebihi $30^{\circ} \mathrm{C}$, sehingga rumah yang suhunya tinggi penghuninya akan mudah terjangkit penyakit, mengurangi daya tahan tubuh atau produktifitas seseorang. Suhu yang panas berpengaruh terhadap tubuh seseorang, penyakit yang terkait dengan udara panas yaitu seperti kram dan edema panas (pembengkakan karena suhu yang tinggi) [10]

Rumah yang menggunakan atap daun yang paling banyak memenuhi persyaratan yaitu dari 36,8\% rumah yang diperiksa hanya 5,9\% rumah yang tidak memenuhi persyaratan. 30,9\% rumah memenuhi syarat hal ini disebabkan sifat daun rumbia yang tidak menyerap kalor 
sehingga tidak ada radiasi dari matahari yang diteruskan ${ }^{[8]}$.

Rumah yang menggunakan atap daun memiliki kelebihan suhu yang memenuhi syarat, sehingga udara dalam ruangan rumah terasa lebih sejuk. Akan tetapi rumah dengan atap daun memiliki kerugian kurang awet dan mudah terbakar.

Pada rumah yang menggunakan atap daun, 7,4\% rumah yang memenuhi syarat kelembaban dan 29,4\% rumah tidak memenuhi syarat kelembaban yaitu $>60 \%$. Hal ini dikarenakan oleh sifat atap daun yang tidak menyerap kalor sehingga kandungan uap air diudara ruangan rumah tinggi, karena tidak terjadi presipitasi (pengembunan/ kondensasi) molekul air yang dikandung udara sehingga muatan air dalam udara tidak menurun dan membuat udara menjadi lembab. Kelembaban yang tinggi dapat meningkatkan daya tahan hidup bakteri patogenesis terutama pada penyakit pernafasan seperti ISPA dan TB paru .

Pada rumah yang menggunakan atap seng dan asbes 57,4\% rumah memenuhi syarat, dikarenakan sifat asbes dan seng menyerap kalor tinggi sehingga

\section{KESIMPULAN DAN SARAN}

Terdapat 3 jenis atap rumah di desa Badaun yaitu atap daun, asbes dan seng. Jumlah rumah di Desa Badaun yaitu 68 buah, 36,8 \% rumah dengan jenis atap 10,3 $\%$ rumah dengan jenis atap asbes dan 52,9 $\%$ rumah dengan jenis atap seng.

Suhu ruangan rumah tertinggi di Desa Badaun $36^{\circ} \mathrm{C}$ dan suhu terendah $25^{\circ} \mathrm{C}$ dengan rata-rata suhu ruangan rumah yang menggunakan atap daun $29,6^{\circ} \mathrm{C}$, atap asbes $32^{\circ} \mathrm{C}$ dan atap seng $32,1{ }^{\circ} \mathrm{C}$. Kelembaban ruangan rumah tertinggi di Desa Badaun 88\% dan kelembaban terendah $46 \%$ dengan rata-rata kelembaban ruangan rumah yang menggunakan atap daun $72,28 \%$, atap asbes $55,7 \%$ dan atap seng $57,3 \%$.

Analisis statistik menunjukkan ada hubungan yang signifikan antara jenis atap rumah (daun, asbes dan seng) dengan suhu dan kelembaban dan rumah yang menggunakan atap jenis asbes dan seng muatan uap air diudara menurun karena terjadi pengembunan molekul air yang dikandung udara[10].

Pada rumah yang menggunakan atap asbes dan seng memiliki kelebihan yaitu kelembaban udara memenuhi syarat sehingga dapat menghambat pertumbuhan bakteri, akan tetapi udara terasa lebih panas karena uap air di udara rendah sehingga membuat ruangan terasa lebih gerah. Rumah yang menggunakan atap asbes dan seng disarankan melengkapi dengan plafon agar panas yang diserap oleh atap dapat tertahan plafon.

Risiko suhu pada rumah yang menggunakan atap jenis asbes dan seng 27 kali suhu lebih tinggi (panas) dibandingkan rumah yang menggunakan atap jenis daun. Jenis atap memiliki radiasi matahari dan serapan kalor yang berbeda, permukaan atap yang menyerap kalor tertinggi ialah seng yaitu $92 \%$ dan asbes 83\%. Semakin besar serapan kalor semakin besar pula panas yang di teruskan ke dalam ruangan, sedangkan atap dengan jenis daun tidak menyerap kalor dan tidak ada panas yang diteruskan[8].

berisiko 27 kali suhu lebih tinggi (panas) dari pada rumah yang menggunakan atap jenis daun.

Bagi masyarakat desa Badaun agar selalu membuka jendela pada pagi hari sehingga sirkulasi udara dalam rumah lancar dan sinar matahari dapat masuk kedalam ruangan rumah. Membuat plafon rumah agar panas yang berasal dari serapan atap dapat tertahan oleh plafon, tidak meletakkan lemari atau barang besar di depan jendela karena akan menghalangi aliran udara serta menanam pohon di sekitar rumah. Untuk penelitian selanjutnya dapat menjadikan ventilasi (sirkulasi udara) atau plafon sebagai faktor yang mempengaruhi suhu dan kelembaban dalam ruangan rumah. 


\section{KEPUSTAKAAN}

1. Karya, Dirjen Cipta. Petunjuk Praktis Rumah Sehat. Jakarta: Departemen Pekerjaan Umum, 1999.

2. Pengaruh Material Dan Bentuk Atap Rumah Tinggal Terhadap Suhu Didalam Rumah. Rury, Nila, Pribadi, IG Oka S and Djoko, Santoso. 2015, Jurnal Arsitektur, pp. 52-63.

3. Rumah Tropis Hemat Energi Bentuk Kepedulian Global Warming. Prianto. 2007, Riptek, pp. 1-10.

4. Sugiyono. Statistika Untuk Penelitian. Bandung : Alfabeta, 2012.

5. Santoso, Imam. Managemen Data Untuk Analisis Data Penelitian Kesehatan. Yogyakarta: Gosyen Publising, 2013.

6. Notoatmodjo. Metodologi Penelitian Kesehatan . Jakarta: Rineka Cipta Cetakan kedua, 2012.
7. Sidney, Siegel and J, Castelan Jr. Nonparametric Statistick For The Behavioral Sciences. Singapura: Mc Graw Hill International Edition, 1988.

8. Menciptakan Kenyamanan Thermal Dalam Bangunan. Talarosha, Basaria. s.l. : Jurnal Teknik Industri Arsitektur Universitas Sumatera Utara, 2005, Vol. 06. 03.

9. Kenyamanan Thermal Pada Bangunan Hunian Tradisional Toraja. Alahudin, Muchlis. ISNN: 2089-6679, Merauke: Jurusan Arsitek Fakultas Teknik Universitas Musamus, 2012, Vol. 01 No 02 .

10. Notoatmodjo. Ilmu Kesehatan Masyarakat. Jakarta: Rineka Cipta, 2003. 
